\title{
Molecular systematics and phylogeography of the gigantic earthworms of the Metaphire formosae species group (Clitellata, Megascolecidae)
}

\author{
Chih-Han Chang ${ }^{\mathrm{a}}$, Si-Min Lin ${ }^{\mathrm{b}}$, Jiun-Hong Chen ${ }^{\mathrm{c}, *}$ \\ a Institute of Zoology, National Taiwan University, 1 Roosevelt Road, Section 4, Taipei 106, Taiwan \\ ${ }^{\mathrm{b}}$ Department of Life Sciences, National Taiwan Normal University, 88 Ting-Chow Rd, Sec 4, Taipei 116, Taiwan \\ ${ }^{\mathrm{c}}$ Institute of Zoology and Department of Life Science, National Taiwan University, 1 Roosevelt Road, Section 4, Taipei 106, Taiwan
}

\section{A R T I C L E I N F O}

\section{Article history:}

Received 13 June 2008

Revised 29 August 2008

Accepted 31 August 2008

Available online 10 September 2008

\section{Keywords:}

Phylogeography

Systematics

Metaphire formosae species group

Megascolecidae

Pheretima complex

\begin{abstract}
A B S T R A C T
The earthworms of the Metaphire formosae species group distributed in Taiwan are members of the Pheretima complex within the Megascolecidae. In this study, the systematics and phylogeography of this species group were investigated using DNA sequences of mitochondrial cytochrome $c$ oxidase subunit I (COI), 16S ribosomal (r)RNA, and NADH dehydrogenase subunit 1 (ND1). The results indicated that the 13 taxa of the $M$. formosae species group form a clade, including a cryptic species discovered in this study. In addition, Metaphire hengchunensis (James et al., 2005) should be regarded as a subspecies of Metaphire paiwanna Tsai et al., 2000, and Metaphire bununa glareosa Tsai et al., 2000 should be elevated to specific status. Phylogeographical inferences showed that allopatric speciation occurred in this species group during the rapid uplift of the main island of Taiwan between 5.0 and 2.5 million years ago. Our analysis exposes non-monophyly within each of the genera Amynthas and Metaphire, and more generally within the Pheretima complex. Further revisions of this speciose complex are urgently needed.
\end{abstract}

(c) 2008 Published by Elsevier Inc.

\section{Introduction}

The Asiatic earthworm genus Metaphire is a member of the Pheretima complex, a speciose group of more than 800 described species within 12 genera belonging to the Megascolecidae (Blakemore, 2002; Easton, 1979, 1982; James, 2005a,b; Sims and Easton, 1972). This genus is widely distributed in East and Southeast Asia with more than 160 species belonging to 25 species groups (Blakemore, 2004; Sims and Easton, 1972). In pheretimoid earthworms, the number and position of the testes are considered to be important taxonomic characters. Generally, most species are holandric (two pairs of testes, one each in segments 10 and 11), but occasionally proandry (one pair of testes in segment 10 ) or metandry (one pair of testes in segment 11) occurs (Sims and Easton, 1972). These differences in testis condition are crucial in within-genus groupings as well as in species identification.

In Metaphire, octothecate species (species bearing four pairs of spermathecae) without secondary copulatory pouches and preclitellar genital markings are further divided into two species groups: the ignobilis species group (holandric) and the stephensoni species group (proandric) (Tsai et al., 2004; Sims and Easton, 1972). However, it has been remarked in many studies that 12 taxa belonging to these two groups share a number of morphological character

\footnotetext{
* Corresponding author.

E-mail addresses: r91225025@ntu.edu.tw (C.-H. Chang), fishdna@ms31.hinet.net (S.-M. Lin), chenjh@ntu.edu.tw (J.-H. Chen).
}

states (Chang and Chen, 2004, 2005a; James et al., 2005; Tsai et al., 2000b, 2004). These taxa are Metaphire trutina Tsai et al. (2003) and Metaphire tahanmonta Chang and Chen (2005a) of the former species group, and Metaphire formosae (Michaelsen, 1922), Metaphire yuhsii (Tsai, 1964), Metaphire paiwanna paiwanna Tsai et al. (2000b), Metaphire paiwanna liliumfordi Tsai et al. (2000b), Metaphire bununa bununa Tsai et al. (2000b), Metaphire bununa glareosa Tsai et al. (2000b), Metaphire taiwanensis Tsai et al. (2004), Metaphire feijani Chang and Chen (2004), Metaphire hengchunensis (James et al., 2005), and Metaphire nanaoensis Chang and Chen (2005a) of the latter. These species all have large body sizes exceeding $30 \mathrm{~cm}$ in length and $10 \mathrm{~mm}$ in width, bluish-gray body coloration, male pores within copulatory pouches with one or two oval pads and four pairs of spermathecae in segments 69. Their burrowing behaviors and casts are also very similar. Morphologically, these species differ only in the condition of the testes, the distance between the paired spermathecal pores, and the structure of the male pores. Accordingly, considering the morphological similarity of the 12 taxa noted above, we herein included these taxa in a newly proposed Metaphire formosae species group, and defined this group as large octothecate Metaphire species without secondary copulatory pouches and preclitellar genital markings, but with oval pads in the male pores.

The $M$. formosae species group is endemic to Taiwan, an island between the Ryukyu Archipelago and the Philippines, and locally nicknamed "snake earthworms" for their large body size. M. formoae and M. yuhsii were described in 1922 and 1964 as Pheretima 
formosae and Pheretima yuhsi, respectively (Michaelsen, 1922; Tsai, 1964). The two species were re-assigned to Amynthas by Sims and Easton (1972) when the authors revised the systematics of the Pheretima complex. After that, re-inspection of specimens led Chang and Chen (2005b) to re-assign the two species to Metaphire due to the presence of copulatory pouches in the male pores. In addition, M. yuhsii was once regarded as a synonym of $M$. formosae (Tsai et al., 2000a), but was later resurrected as a valid species (Chang and Chen, 2005b) by the distinctive differences in the distances between the paired spermathecal pores and divergences of the mitochondrial cytochrome $c$ oxidase subunit I (COI) gene, the former being the only morphological difference between the two species.

The other 10 taxa of this species group were described recently (Chang and Chen, 2004, 2005a; James et al., 2005; Tsai et al., 2000b, 2003, 2004). Metaphire trutina was described as a sexthecate species (species bearing only three pairs of spermathecae) (Tsai et al., 2003), but as the octothecate Metaphire yuanpowa Chang and Chen (2005a) was regarded as a synonym of M. trutina (Blakemore et al., 2006), this species was proved to be an originally octothecate earthworm. M. hengchunensis was described as a member of the genus Amynthas (James et al., 2005). However, the assignment of this species to Amynthas was due to different criteria regarding the presence and absence of copulatory pouches (James et al., 2005), which is the only diagnostic character between Metaphire and Amynthas (for detailed discussion on this dispute, see James, 2005a,b and James et al., 2005). By using the same criteria as those used in M. trutina, M. tahanmonta and M. taiwanensis, we tentatively re-assigned this species to Metaphire. Considering the blooming of new taxa and names proposed in recent years, and the confusion that previous studies may lead to, a comprehensive taxonomic revision of this species group using molecular phylogenetic approaches is necessary for future systematic and biodiversity studies.

The morphological similarity among these earthworms suggests that they comprise a group of closely related species. Recently, Chang and Chen (2005a) hypothesized the monophyly of M. nanaoensis, M. tahanmonta, M. formosae, M. paiwanna paiwanna, M. paiwanna liliumfordi, M. bununa bununa, M. bununa glareosa, $M$. taiwanensis, and M. trutina by comparing their morphology. Subsequently, the monophyly of M. formosae, M. yuhsii, M. paiwanna paiwanna, $M$. bununa bununa, $M$. trutina, and $M$. tahanmonta was supported by molecular studies using the COI gene (Chang and Chen, 2005b). However, the relationships among these species were not unraveled due to insufficient sequence lengths analyzed. Using a molecular phylogenetic approach, we attempted to clarify the relationships.

The molecular phylogenetic analyses of these earthworms in a geographical context can also provide opportunities to test speciation hypotheses of these species. The M. formosae species group has been suggested to be derived from their mainland siblings in Southeast Asia or southeastern China (Chang and Chen, 2005a). Most of these species show an allopatric distribution in Taiwan (Chang and Chen, 2004, 2005a,b). This allopatric distribution suggests possible causal relationships between the speciation of these species and the geological history of this island. Recently, DNA barcoding has been used to evaluate morphologically similar earthworm species (Chang and Chen, 2005b; Chang et al., 2007; Pérez-Losada et al., 2005), and systematic revisions of some earthworm groups were also conducted using molecular phylogenetic analyses (Heethoff et al., 2004; James, 2005b; Jamieson et al., 2002; Pop et al., 2003, 2007) Nevertheless, no phylogeographical hypothesis concerning speciation of earthworms was inferred. In this study, we demonstrate the first case to use molecular phylogenetic approaches on the evolutionary and phylogeographical study of closely related earthworm species. We used mitochondrial DNA sequences to study the systematics and evolution of the
M. formosae species group. We revised the taxonomy of these species using the COI sequences, the DNA barcode as proposed by Hebert et al. (2003a,b), and evaluated the validity of the $M$. formosae species group proposed herein. We then hypothesized the phylogeny of the $M$. formosae species group and made phylogeographical inferences.

\section{Material and methods}

\subsection{Sample collection and preservation}

Earthworms of the $M$. formosae species group were collected throughout Taiwan during 2000-2004. In our analyses (see below), $M$. hengchunensis was regarded as a subspecies of M. paiwanna, $M$. bununa glareosa was elevated to specific status, namely $M$. glareosa, and a cryptic species, Metaphire sp. was revealed. Therefore, 11 species in total of the $M$. formosae species group were used, including M. formosae, M. yuhsii, M. paiwanna, M. bununa, M. taiwanensis, M. trutina, M. feijani, M. nanaoensis, M. tahanmonta, M. glareosa and Metaphire sp.. Moreover, M. paiwanna is composed of three subspecies, namely M. paiwanna paiwanna, M. paiwanna liliumfordi, and $M$. paiwanna hengchunensis, and all three subspecies were included in the analysis. Samples were anesthetized in a $10 \%$ ethanol solution; some muscle tissues were isolated and preserved in a $70 \%$ or $95 \%$ ethanol solution for DNA extraction; the residual earthworm samples were fixed in $10 \%$ formalin and then preserved in a $70 \%$ ethanol solution. Some other pheretimoid earthworms collected in Taiwan were treated using the same procedures for the phylogenetic analysis (Table 1 ).

\subsection{DNA extraction, polymerase chain reaction (PCR), and DNA sequencing}

Muscle tissues were washed with distilled water, homogenized in liquid nitrogen, and digested in digestion buffer (10 mM Tris$\mathrm{HCl}, 2 \mathrm{mM}$ dihydrate EDTA, $10 \mathrm{mM} \mathrm{NaCl}, 10 \mathrm{mg} / \mathrm{ml} \mathrm{DTT}, 1 \% \mathrm{SDS}$, and $0.4 \mathrm{mg} / \mathrm{ml}$ protease $\mathrm{K}$ ) at $50{ }^{\circ} \mathrm{C}$ for $15 \sim 30 \mathrm{~min}$. Total DNA was extracted from the digested tissue-buffer solution with a standard phenol/chloroform extraction method followed by ethanol precipitation (Palumbi et al., 1991). The ethanol-precipitated DNA was dissolved in distilled water, checked with $1.0 \%$ agarose gel electrophoresis, and stored at $-20^{\circ} \mathrm{C}$.

Several DNA fragments from the earthworm mitochondrial genome were amplified by PCR, including COI, 16S ribosomal (r)RNA, and NADH dehydrogenase subunit 1 (ND1). All primer sequences were listed in Table 2. For COI, two partially overlapping fragments were amplified by LCO1490 and HCO2198 (Folmer et al., 1994) for the $5^{\prime}$ fragment and by COIF0622 and COIR1117 for the $3^{\prime}$ fragment. When the second primer pair failed to work, instead of COIR1117, COIR1294 was used for M. trutina and Metaphire schmardae, and COIR1102 was used for M. feijani. For 16S rRNA, the universal primers 16Sar and 16Sbr (Hillis and Moritz, 1990) were used. For ND1, the primers LeuND1F and IleND1R designed in this study were used. The amplifications were carried out in a $50-\mu$ lotal volume using one cycle at $94{ }^{\circ} \mathrm{C}$ for $1 \mathrm{~min}$, followed by 35 cycles of denaturation for $30 \mathrm{~s}$ at $94^{\circ} \mathrm{C}$, annealing for $30 \mathrm{~s}$ at $52{ }^{\circ} \mathrm{C}$, and extension for $90 \mathrm{~s}$ at $72{ }^{\circ} \mathrm{C}$, with a final cycle at $72{ }^{\circ} \mathrm{C}$ for $10 \mathrm{~min}$.

The PCR products were checked using $1.0 \%$ agarose gel electrophoresis and sequenced in both directions using the same primers as for PCR. Sequencing was performed with a BigDye Terminator Cycle Sequencing Ready Reaction Kit, V3.1 (Applied Biosystems, CA, USA). Products were analyzed on an ABI 3730 XL DNA Analyzer (Applied Biosystems). The sequence of each sample was verified through a comparison of complementary light and heavy strands and double-checked by eye. 
Table 1

Samples used in the phylogenetic study and the corresponding GenBank Accession Numbers

\begin{tabular}{|c|c|c|c|c|c|c|}
\hline \multirow[t]{2}{*}{ Species } & \multirow[t]{2}{*}{ Locality } & \multirow[t]{2}{*}{ Sample no. } & \multirow[t]{2}{*}{ Voucher no. } & \multicolumn{3}{|c|}{ Accession no. of haplotypes } \\
\hline & & & & $\mathrm{COI}$ & ND1 & $16 S$ \\
\hline \multirow[t]{17}{*}{ Metaphire yuhsii } & Hsintien, Taipei County & B0665 & Afo-65 & AY739309a & & \\
\hline & Wulai, Taipei County & B0650 & Afo-50 & AY739310 & & \\
\hline & Shouyi, Taipei County & B0604 & Afo-4 & AY739311 & & \\
\hline & Wanli, Taipei County & B0601 & Afo-1 & AY960799 & AY960786 & AY960812 \\
\hline & Tamsui, Taipei County & B0612 & Afo-12 & AY739313 & & \\
\hline & Sanchih, Taipei County & B0611 & Afo-11 & AY739314 & & \\
\hline & Tuchen, Taipei County & B0663 & Afo- 63 & AY739315 & & \\
\hline & Sanshia, Taipei County & B0607 & Afo-7 & AY739316 & & \\
\hline & Mucha, Taipei City & B0602 & Afo-2 & AY739317 & & \\
\hline & Nangang, Taipei City & B0625 & Afo-25 & AY739318 & & \\
\hline & Keelung City & B0624 & Afo-24 & AY739319 & & \\
\hline & Taoyuan, Taoyuan County & B0660 & Afo- 60 & AY739320 & & \\
\hline & Lungtan, Taoyuan County & B0619 & Afo-19 & AY739321 & & \\
\hline & Fushing, Taoyuan County & B0657 & Afo-57 & AY739322 & & \\
\hline & Chudong, Hsinchu County & B0628 & Afo-28 & AY739323 & & \\
\hline & Guanhsi, Hsinchu County & B0659 & Afo-59 & AY739324 & & \\
\hline & Jianshi, Hsinchu County & B0637 & Afo-37 & AY739325 & & \\
\hline \multirow[t]{9}{*}{ M. formosae } & Yamgmei, Taoyuan County & B1801 & AfoTII-1 & AY960807 & AY960794 & AY960820 \\
\hline & Baushan, Hsinchu County & B1808 & AfoTII-8 & AY739327 & & \\
\hline & Sanwan, Miaoli County & B1811 & AfoTII-11 & AY739328 & & \\
\hline & Sanyi, Miaoli County & B1847 & AfoTII-47 & AY739329a & & \\
\hline & Nanchuang, Miaoli County & B1855 & AfoTII-55 & AY739330 & & \\
\hline & Heping, Taichung County & B1875 & AfoTII-75 & AY739331 ${ }^{\mathrm{a}}$ & & \\
\hline & Guoshing, Nantou County & B1867 & AfoTII-67 & AY739332 & & \\
\hline & Shinyi, Nantou County & B18105 & AfoTII-105 & $\mathrm{AY} 739333^{\mathrm{a}}$ & & \\
\hline & Mayshan, Chiayi County & B1899 & AfoTII-99 & AY739334 & & \\
\hline \multirow[t]{4}{*}{ M. tahanmonta } & Taoyuan, Kaohsiung County & B0830 & $\mathrm{sp} 40-2$ & AY739335 & & \\
\hline & Taoyuan, Kaohsiung County & B0831 & sp40-3 & AY960800 & AY960787 & AY960813 \\
\hline & Chunri, Pingtung County & B0807 & sp40-1 & AY962115 & & \\
\hline & Taoyuan, Kaohsiung County & B0874 & sp40-4 & AY962116 & & \\
\hline M. paiwanna paiwanna & Liouguei, Kaohsiung County & B0827 & Mpa-45 & AY739336 ${ }^{a}$ & & \\
\hline & Sandimen, Pingtung County & B1906 & Mpa-6 & AY962117 & & \\
\hline & Majia, Pingtung County & B1911 & Mpa-11 & AY962118 & & \\
\hline & Taiwu, Pingtung County & B1920 & Mpa-20 & AY962119 & & \\
\hline & Taiwu, Pingtung County & B1930 & Mpa-30 & AY962120 & & \\
\hline & Chunri, Pingtung County & B1941 & Mpa-41 & AY962121 & & \\
\hline & Taimali, Taitung County & B08156 & Mpa-55 & AY962133 & & \\
\hline & Taimali, Taitung County & B08157 & Mpa-56 & AY962135 & & \\
\hline & Dazen, Taitung County & B08159 & Mpa-57 & AY962136 & & \\
\hline & Dazen, Taitung County & B08174 & Mpa-59 & AY962137 & & \\
\hline & Dawu, Taitung County & B08163 & Mpa-58 & AY962138 & & \\
\hline M. paiwanna hengchunensis (M. hengchunensis) & Nanjenshan, Pingtung County & B1901 & Mph-1 & AY962122 & & \\
\hline & Nanjenshan, Pingtung County & B08179 & Mph-6 & AY962123 & & \\
\hline & Nanjenshan, Pingtung County & B08180 & Mph-7 & AY962124 & & \\
\hline M. paiwanna liliumfordi & Shulin, Hualien County & B0816 & Mpl-3 & AY962125 & & \\
\hline & Guangfu, Hualien County & B0812 & Mpl-2 & AY962126 & & \\
\hline & Juoshi, Hualien County & B0847 & Mpl-18 & AY962127 & & \\
\hline & Juoshi, Hualien County & B0845 & Mpl-16 & AY962128 & & \\
\hline & Yuli, Hualien County & B0857 & Mpl-26 & AY962129 & & \\
\hline & Fengbin, Hualien County & B0814 & Mpl-24 & AY962130 & & \\
\hline & Fengbin, Hualien County & B0853 & Mpl-25 & AY962131 & & \\
\hline & Beinan, Taitung County & B08101 & Mpl-27 & AY960802 & AY960789 & AY960815 \\
\hline & Beinan, Taitung County & B0810 & Mpl-1 & AY962132 & & \\
\hline & Taimali, Taitung County & B08154 & Mpl-28 & AY962134 & & \\
\hline M. bununa & Heping, Taichung County & B08145 & Mbu-9 & AY739337 ${ }^{\mathrm{a}}$ & & \\
\hline & Datong, Ilan County & B0815 & Mbu-3 & AY962139 & & \\
\hline & Renai, Nantou County & B0802 & Mbu-1 & AY962140 & & \\
\hline & Alishan, Chiayi County & B08143 & Mbu-7 & AY960804 & AY960791 & AY960817 \\
\hline M. trutina & Wulai, Taipei County & B0729 & sp21-29 & AY739338 & & \\
\hline & Pinglin, Taipei County & B0704 & sp21-4 & AY962144 & & \\
\hline & Neihu, Taipei City & B0701 & sp21-1 & AY962145 & & \\
\hline & Hsiaochaochi, Ilan County & B0803 & sp21-13 & AY962146 & & \\
\hline & Jianshi, Hsinchu County & B08110 & sp21-34 & AY962147 & & \\
\hline & Wufeng, Hsinchu County & B0714 & sp21-14 & AY960808 & AY960795 & AY960821 \\
\hline & Nanchuang, Miaoli County & B0726 & sp21-26 & AY962148 & & \\
\hline M. nanaoensis & Shulin, Hualien County & B1315 & sp62-2 & AY962149 & & \\
\hline & Shulin, Hualien County & B1323 & sp62-5 & AY962150 & & \\
\hline & Shulin, Hualien County & B1314 & sp62-1 & AY960805 & AY960792 & AY960818 \\
\hline & Nanao, Ilan County & B1322 & sp39-22 & AY962151 & & \\
\hline & Nanao, Ilan County & B1307 & sp39-7 & AY962152 & & \\
\hline & Nanao, Ilan County & B1306 & sp39-6 & AY962153 & & \\
\hline & Nanao, Ilan County & B1320 & sp39-20 & AY962154 & & \\
\hline M. taiwanensis & Renai, Nantou County & B1504 & Mta-4 & AY962155 & & \\
\hline & Renai, Nantou County & B1505 & Mta-5 & AY962156 & & \\
\hline
\end{tabular}


Table 1 (continued)

\begin{tabular}{|c|c|c|c|c|c|c|}
\hline \multirow[t]{2}{*}{ Species } & \multirow[t]{2}{*}{ Locality } & \multirow[t]{2}{*}{ Sample no. } & \multirow[t]{2}{*}{ Voucher no. } & \multicolumn{3}{|c|}{ Accession no. of haplotypes } \\
\hline & & & & $\mathrm{COI}$ & ND1 & $16 S$ \\
\hline & Renai, Nantou County & B1502 & Mta-2 & AY960806 & AY960793 & AY960819 \\
\hline & Yuanshan, Ilan County & B1605 & sp22-5 & AY962157 & & \\
\hline & Yuanshan, Ilan County & B1607 & sp22-7 & AY962158 & & \\
\hline \multirow[t]{5}{*}{ M. feijani } & Majia, Pingtung County & B2401 & sp92-1 & AY960809 & AY960796 & AY960822 \\
\hline & Majia, Pingtung County & B2402 & sp92-2 & AY962159 & & \\
\hline & Majia, Pingtung County & B2403 & sp92-3 & AY962160 & & \\
\hline & Wutai, Pingtung County & B2404 & sp92-4 & AY962161 & & \\
\hline & Wutai, Pingtung County & B2405 & sp92-5 & AY962162 & & \\
\hline \multirow{5}{*}{$\begin{array}{l}\text { Metaphire sp. (morphologically identified } \\
\text { as M. paiwanna paiwanna) }\end{array}$} & Taoyuan, Kaohsiung County & В0873 & sp90-2 & AY962163 & & \\
\hline & Taoyuan, Kaohsiung County & B08147 & sp90-5 & AY962164 & & \\
\hline & Taoyuan, Kaohsiung County & В0833 & sp90-1 & AY960801 & AY960788 & AY960814 \\
\hline & Taoyuan, Kaohsiung County & B0832 & sp90-3 & AY962165 & & \\
\hline & Taoyuan, Kaohsiung County & B0834 & sp90-4 & AY962166 & & \\
\hline \multirow[t]{18}{*}{ M. glareosa (M. bununa glareosa) } & Shitzi, Pingtung County & B08150 & Mam-18 & AY962167 & & \\
\hline & Shitzi, Pingtung County & B08149 & Mam-17 & AY962168 & & \\
\hline & Dazen, Taitung County & B08169 & Mam-21 & AY962169 & & \\
\hline & Ruisui, Hualien County & B0813 & Mam-2 & AY962170 & & \\
\hline & Ruisui, Hualien County & B0856 & Mam-8 & AY962171 & & \\
\hline & Yuli, Hualien County & B0861 & Mam-3 & AY962172 & & \\
\hline & Yuli, Hualien County & В0863 & Mam-6 & AY962173 & & \\
\hline & Fuli, Hualien County & B08148 & Mam-16 & AY962174 & & \\
\hline & Dunghe, Taitung County & B0872 & Mam-4 & AY962175 & & \\
\hline & Luyee, Taitung County & B0875 & Mam-9 & AY962176 & & \\
\hline & Beinan, Taitung County & В0879 & Mam-10 & AY962177 & & \\
\hline & Taimali, Taitung County & B08108 & Mam-12 & AY962178 & & \\
\hline & Taimali, Taitung County & B08151 & Mam-19 & AY962179 & & \\
\hline & Taimali, Taitung County & B08106 & Mam-11 & AY960803 & AY960790 & AY960816 \\
\hline & Chupun, Taitung County & B08113 & Mam-15 & AY962180 & & \\
\hline & Chupun, Taitung County & B08112 & Mam-14 & AY962181 & & \\
\hline & Chupun, Taitung County & B08111 & Mam-13 & AY962182 & & \\
\hline & Chupun, Taitung County & B08166 & Mam-20 & AY962183 & & \\
\hline M. californica & Taipei City & B0106 & Mca-6 & AY960810 & AY960797 & AY960823 \\
\hline M. schmardae & Taipei City & B2502 & Msc-2 & AY960811 & AY960798 & AY960824 \\
\hline M. posthuma & Hsintien, Taipei County & В0203 & Мро-3 & & & AY960825 \\
\hline Amynthas binoculatus & Baushan, Hsinchu County & B2111 & sp61-11 & AY962184 & & AY968683 \\
\hline \multirow[t]{2}{*}{ A. carnosus } & Chaochi, Ilan County & B1201 & sp34-1 & & & AY960830 \\
\hline & Wulai, Taipei County & B1205 & sp34-5 & AY962185 & & \\
\hline A. aspergillum & Guting, Taipei City & В0301 & Aas-1 & & & AY960826 \\
\hline A. incongruus & Wanli, Taipei County & B0503 & Ain-3 & & & AY960827 \\
\hline A. robustus & Yuanshan, Ilan County & B1101 & Aro-1 & & & AY960829 \\
\hline A. gracilis & Hsintien, Taipei County & B1005 & Agr-5 & & & AY960828 \\
\hline Begemius queenslandicus & & & & & & $\mathrm{AF} 406578^{\mathrm{a}}$ \\
\hline \multirow[t]{2}{*}{ Pontodrilus litoralis } & & & & AF003256 ${ }^{a}$ & & \\
\hline & & & & & & $\mathrm{AF} 406586^{\mathrm{a}}$ \\
\hline Fletcherodrilus sigillatus & & & & & & $\mathrm{AF} 406588^{\mathrm{a}}$ \\
\hline Spenceriella cormieri & & & & & & $\mathrm{AF} 406589^{\mathrm{a}}$ \\
\hline Spenceriella sp. & & & & & & $\mathrm{AF} 406572^{\mathrm{a}}$ \\
\hline Diporochaeta sp. & & & & & & $\mathrm{AF} 406574^{\mathrm{a}}$ \\
\hline Perionychella kershawi & & & & & & AF406567 ${ }^{\mathrm{a}}$ \\
\hline Digaster lingi & & & & & & $\mathrm{AF} 406583^{\mathrm{a}}$ \\
\hline Dichogaster saliens & & & & & & $\mathrm{AF} 406573^{\mathrm{a}}$ \\
\hline Dic. samjamesi & & & & & & AF406571 ${ }^{\mathrm{a}}$ \\
\hline Terrisswalkerius grandis & & & & & & AF406566 ${ }^{a}$ \\
\hline T. moritzi & & & & & & $\mathrm{AF} 406560^{\mathrm{a}}$ \\
\hline T. millamilla & & & & & & $\mathrm{AF} 406565^{\mathrm{a}}$ \\
\hline Perionyx excavatus & & & & & & $\mathrm{AF} 406582^{\mathrm{a}}$ \\
\hline Didymogaster sylvaticus & & & & & & $\mathrm{AF} 406575^{\mathrm{a}}$ \\
\hline Lumbricus terrestris & & & & $\mathrm{U} 24570^{\mathrm{a}}$ & $\mathrm{U} 24570^{\mathrm{a}}$ & $\mathrm{U} 24570^{\mathrm{a}}$ \\
\hline
\end{tabular}

a Sequences retrieved from GenBank for analyses.

\subsection{Sequence alignment, phylogenetic analysis, and topological tests}

The sequences obtained were checked by aligning the sequencing results with the corresponding sequences of Lumbricus terrestris in GenBank using the default settings of Clustal X 1.81 (Thompson et al., 1997) and then submitted to GenBank (Table 1). All ingroup sequences used in Chang and Chen (2005b) and sequences of $L$. terrestris and some other megascolecid earthworms were retrieved from GenBank (Table 1) and used in the phylogenetic analysis. Alignments were performed using the default settings of Clustal X 1.81 and then manually adjusted using BioEdit
(Hall, 1999). Gaps and ambiguously aligned regions in the DNA sequences were eliminated in all of the following analyses. Metaphire tschiliensis tschiliensis, Dichogaster samjamesi or L. terrestris was used as the outgroup in the analyses. The $5^{\prime}$ fragment of COI amplified using the primer pair, LCO1490 and HCO2198, was first used to reexamine the taxon status; then, one specimen for each species identified in the COI analysis was chosen and used in the following analyses. The 16S rRNA gene sequences were used to test the hypothesis of a monophyletic $M$. formosae species group. The $16 \mathrm{~S}$ rRNA gene was chosen instead of COI because of the availability of sequences in GenBank and the slower evolutionary rate of this 
Table 2

Primers used in the phylogenetic analyses

\begin{tabular}{|c|c|c|}
\hline Primer & Sequence & Reference \\
\hline LCO1490 & 5'-GGT CAA CAA ATC ATA AAG ATA TTG G-3' & Folmer et al., 1994 \\
\hline HCO2198 & $5^{\prime}$-TAA ACT TCA GGG TGA CCA AAA AAT CA-3' & Folmer et al., 1994 \\
\hline COIF0622 & $5^{\prime}$-ACA GAT CGA AAC CTA AAT AC-3' & This study \\
\hline COIR1117 & 5'-ATT CTC AAC ACG TAG TGG AAG TG-3' & This study \\
\hline COIR1294 & 5'-TCA GAA TAT CGC CGA GGT ATA CC-3' & This study \\
\hline COIR1102 & $5^{\prime}$-TGA AAA TGT GCT ACN ACA TAG TA-3' & This study \\
\hline 16Sar & $5^{\prime}$-CGC CTG TTT ATC AAA AAC AT- $3^{\prime}$ & Hillis and Moritz, 1990 \\
\hline $16 \mathrm{Sbr}$ & 5'-CCG GTC TGA ACT CAG ATC ACG T-3' & Hillis and Moritz, 1990 \\
\hline LeuND1F & 5'-CAA GAT GGC AGA GTG CCA-3' & This study \\
\hline IleND1R & 5'-TAA CGT CAT CAG AGT TAT CCG-3' & This study \\
\hline
\end{tabular}

gene. The combined sequence set of 16S rRNA, COI, and ND1 was then used to reconstruct the phylogeny of the $M$. formosae species group. Before combining the nucleotide sequences of the three genes, the incongruence length difference test (ILD; Farris et al., 1994) was conducted to check whether all of the sequences were suitable for combination. Since the result of the ILD test was not significant $(P=0.38)$, the three genes were combined.

In the phylogenetic analyses, the most-appropriate model of DNA substitution was chosen using hierarchical likelihood ratio tests with PAUP 4.0b10 (Swofford, 2000) and Modeltest 3.0 (Posada and Crandall, 1998). For the $5^{\prime}$ fragment of COI, the TVM model (Rodríguez et al., 1990) with invariable sites of 0.5907 and a gamma shape parameter of 0.9298 (TVM + I + G) was chosen (Base frequencies: A, 0.3744; C, 0.2120; G, 0.1451; and T, 0.2684. Substitution rates: A-C, 1.2390; A-G, 11.5090; A-T, 0.6402; C-G, 0.2470; C-T, 11.5090; and G-T, 1.0000). For 16S rRNA, the general-time reversible model (Tavaŕe, 1986) with invariable sites of 0.3930 and a gamma shape parameter of $0.4588(\mathrm{GTR}+\mathrm{I}+\mathrm{G}$ ) was chosen (Base frequencies: A, 0.4365; C, 0.1458; G, 0.1492; and T, 0.2684. Substitution rates: A-C, 1094.7264; A-G, 2152.7852; A-T, 1349.1843; CG, 285.2955; C-T, 6401.8551; and G-T, 1.0000). The maximum likelihood (ML) analysis was performed using PAUP $4.0 \mathrm{~b} 10$ with heuristic searches, starting trees obtained by neighbor joining (NJ), and TBR branch swapping. Three different approaches were used to evaluate the reliability of the inferred phylogenetic tree. First, Bayesian analysis was applied to generate a posterior probability distribution using the Metropolis-coupled Markov Chain Monte Carlo (MCMC) with MrBayes 3.0b4 (Huelsenbeck and Ronquist, 2001; Ronquist and Huelsenbeck, 2003). The search was run for $1 \times 10^{6}$ generations, and every 500th tree was sampled after a burn-in of $10^{5}$ generations. Posterior probabilities for each branch were calculated from the sampled trees. Second, an NJ analysis with 1000 bootstrap replicates was conducted using PAUP 4.0b10. Third, an unweighed maximum parsimony (MP) analysis with 1000 bootstrap replicates was performed using PAUP 4.0b10 with heuristic searches, random starting trees, 10 random additions of sequences, and TBR branch swapping. Because of the extensive computational time, the maximum number of trees saved was limited to 1000 in the COI dataset in this procedure.

For the combined dataset of COI, ND1, and 16S rRNA, TamuraNei's model (Tamura and Nei, 1993) with invariable sites of 0.5446 and a gamma shape parameter of $0.9102(\operatorname{TrN}+\mathrm{I}+\mathrm{G})$ was the most-appropriate model of DNA substitution. Parameters were set to unequal base frequencies (A, 0.3473; C, 0.2200; G, 0.1294; and $\mathrm{T}, 0.3033)$, unequal transition rates $(\mathrm{A}-\mathrm{G}, 9.4422$; and $\mathrm{C}-\mathrm{T}$, 11.2124), and equal transversion rates (1.0000). The ML analyses were performed using random starting trees and 100 random additions of sequences with the other settings the same as those used in the COI and 16S rRNA analyses. In addition, the same three approaches used in the 16S rRNA analysis were employed to evaluate the reliability of the inferred phylogenetic tree except 100 instead of 10 random additions of sequences were used in the unweighed MP analysis.

The ML tree with the highest $\ln (L)$ score was compared to alternative tree hypotheses. The Shimodaira-Hasegawa (SH) test (Shimodaira and Hasegawa, 1999) was performed using PAUP 4.0b10 with 1000 bootstrap replications.

\section{Results}

\subsection{Sequence characteristics}

For the $5^{\prime}$ fragment of $\mathrm{COI}, 94$ haplotypes were observed from 104 individuals of the M. formosae species group (Table 1). All haplotypes were $535 \mathrm{bp}$ in length, without insertions or deletions. Within the $M$. formosae species group, the mean interspecific sequence divergences ranged from $12.9 \%$ (M. bununa vs. M. feijani) to $27.7 \%$ (M. trutina vs. M. yuhsii) (Table 3).

Table 3

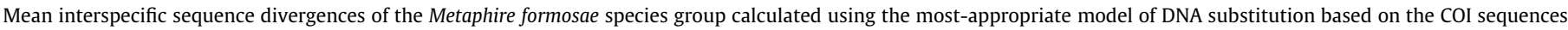
(lower left) and the combined sequences of COI, ND1, and 16S rRNA (upper right)

\begin{tabular}{|c|c|c|c|c|c|c|c|c|c|c|c|}
\hline & MSP & FEI & PAI & BUN & TAH & TRU & TAI & GLA & NAN & YUH & FOR \\
\hline MSP & & 0.086 & 0.087 & 0.095 & 0.102 & 0.105 & 0.109 & 0.110 & 0.114 & 0.109 & 0.125 \\
\hline FEI & 0.151 & & 0.086 & 0.088 & 0.095 & 0.110 & 0.107 & 0.107 & 0.111 & 0.116 & 0.120 \\
\hline PAI & 0.164 & 0.147 & & 0.080 & 0.086 & 0.091 & 0.096 & 0.100 & 0.104 & 0.105 & 0.115 \\
\hline BUN & 0.192 & 0.129 & 0.156 & & 0.086 & 0.095 & 0.097 & 0.100 & 0.099 & 0.110 & 0.115 \\
\hline TAH & 0.201 & 0.155 & 0.156 & 0.152 & & 0.093 & 0.105 & 0.102 & 0.095 & 0.112 & 0.121 \\
\hline TRU & 0.241 & 0.241 & 0.190 & 0.184 & 0.174 & & 0.097 & 0.109 & 0.098 & 0.113 & 0.125 \\
\hline TAI & 0.256 & 0.230 & 0.225 & 0.206 & 0.217 & 0.241 & & 0.105 & 0.099 & 0.110 & 0.122 \\
\hline GLA & 0.224 & 0.226 & 0.197 & 0.204 & 0.216 & 0.222 & 0.253 & & 0.095 & 0.108 & 0.116 \\
\hline NAN & 0.232 & 0.178 & 0.234 & 0.199 & 0.192 & 0.232 & 0.228 & 0.200 & & 0.109 & 0.117 \\
\hline YUH & 0.216 & 0.205 & 0.223 & 0.193 & 0.197 & 0.277 & 0.275 & 0.222 & 0.224 & & 0.122 \\
\hline FOR & 0.226 & 0.222 & 0.193 & 0.207 & 0.215 & 0.249 & 0.233 & 0.242 & 0.239 & 0.228 & \\
\hline
\end{tabular}

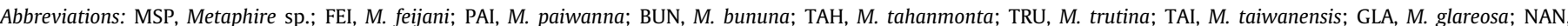
M. nanaoensis; YUH, M. yuhsii; FOR, M. formosae. 


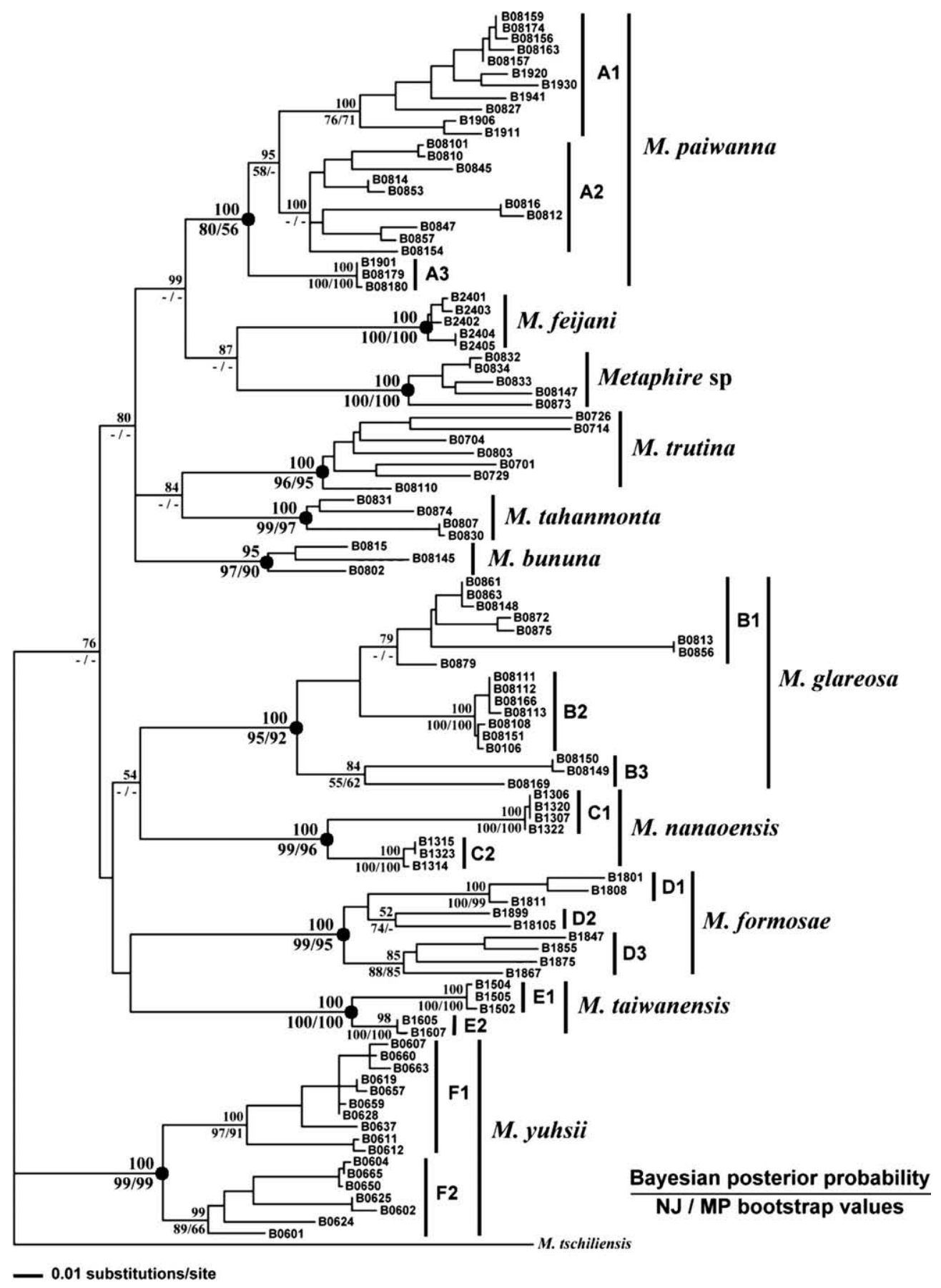

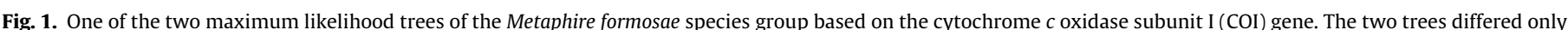

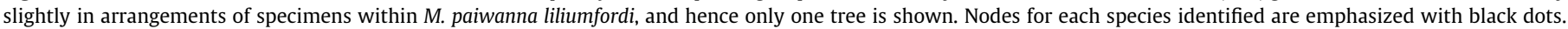

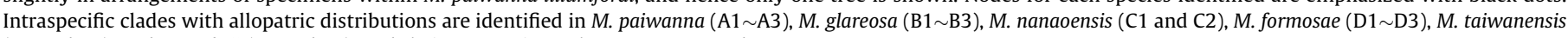
(E1 and E2), and M. yuhsii (F1 and F2), and their supporting values are presented.

The lengths of the $M$. formosae species group 16S rRNA gene haplotypes ranged from 385 to $388 \mathrm{bp}$. The lengths of the pheretimoid earthworm 16S rRNA gene haplotypes ranged from 381 to $388 \mathrm{bp}$. The total aligned sequences were $395 \mathrm{bp}$, with insertions or deletions of $1 \sim 2 \mathrm{bp}$.

The lengths of the combined sequences ranged from 2435 to $2442 \mathrm{bp}$, including 456 464 bp from the 16S rRNA gene, 1,056 bp from the COI gene, and 922 or $925 \mathrm{bp}$ from the ND1 gene. The aligned sequences were $2453 \mathrm{bp}$, with insertions or deletions of $1 \sim 4$ bp due to a 3-bp insertion of the L. terrestris ND1 gene (corresponding to an amino acid) and variations in the $16 \mathrm{~S}$ rRNA gene fragments. Within the M. formosae species group, interspecific sequence divergences ranged from $8 \%$ (M. paiwanna vs. M. bununa) to $12.5 \%$ ( $M$. formosae vs. M. trutina and M. formosae vs. Metaphire sp.) (Table 3).

\subsection{Phylogenetic analyses}

In the analyses using the $5^{\prime}$ fragment of COI, the ML analysis resulted in two trees with the highest $\ln (L)$ score of -6202.47 . The two trees differed only slightly in arrangements of specimens within M. paiwanna liliumfordi, and hence only one tree is shown (Fig. 1). The posterior probabilities from the Bayesian analysis and the bootstrap values from the MP and $\mathrm{NJ}$ analyses were plotted on the ML tree (Fig. 1). The phylogenetic analysis based on the $5^{\prime}$ 
Table 4

Mean intraspecific sequence divergences between clades within Metaphire paiwanna, M. glareosa, M. nanaoensis, M. formosae, M. taiwanensis and M. yuhsii calculated using the most-appropriate model of DNA substitution based on the COI sequences

\begin{tabular}{lll}
\hline Species & Clade pair & Sequence divergence \\
\hline M. paiwanna & A1 and A2 & 0.083 \\
& A1 and A3 & 0.095 \\
M. glareosa & A2 and A3 & 0.094 \\
& B1 and B2 & 0.081 \\
B. nanaoensis & B2 and B3 & 0.118 \\
M. formosae & C1 and C2 & 0.135 \\
& D1 and D2 & 0.090 \\
M. taiwanensis & D1 and D3 & 0.093 \\
M. yuhsii & D2 and D3 & 0.118 \\
\hline
\end{tabular}

fragment of COI revealed that there are 11 monophyletic groups, corresponding to 11 species, within the $M$. formosae species group (Fig. 1). These monophyletic groups were largely congruent with morphological species previously identified but with a few exceptions. A cryptic species morphologically identified as M. paiwanna paiwanna was discovered, namely Metaphire sp.. M. bununa glareosa was elevated to a specific status, namely M. glareosa (see Discussion). In addition, intraspecific clades for M. paiwanna, M. taiwanensis, M. nanaoensis, M. formosae, M. yuhsii, and M. glareosa were defined (Fig. 1), and their genetic divergences were estimated (Table 4) for further discussion. However, although the COI fragment proved to be useful in species clustering, it showed poor resolution for interpreting the interspecific relationships.

In the analyses using $16 \mathrm{~S}$ rRNA, the ML analysis resulted in a tree with the highest $\ln (L)$ score of -3657.68 (Fig. 2). The posterior probabilities from the Bayesian analysis and bootstrap values from the MP and NJ analyses were plotted on the ML tree (Fig. 2). The analysis of the 16S rRNA gene sequence supported the $M$. formosae species group being monophyletic within the Pheretima complex. Furthermore, the monophyly of the Pheretima complex within the Megascolecidae was also supported (Fig. 2).

In the combined analyses using COI, ND1, and 16S rRNA, the ML analysis resulted in a tree with the highest $\ln (L)$ score of -13389.88 (Fig. 3). The posterior probabilities from the Bayesian analysis and the bootstrap values from the MP and NJ analyses were plotted on the ML tree (Fig. 3). In addition, three groups within the $M$. formosae species group were defined for further discussion: at the basal part of the inferred phylogenetic tree is the western hill group, including $M$. formosae and M. yuhsii; the monophyletic eastern mountain group includes $M$. nanaoensis and $M$. glareosa; the monophyletic western mountain group includes $M$. paiwanna, M. bununa, M. trutina, M. taiwanensis, M. tahanmonta, M. feijani and Metaphire sp. (Fig. 3).

To test if M. paiwanna and Metaphire sp. comprise a monophyletic group, the $\mathrm{SH}$ test was applied. In addition, the monophyly of species with dorsally positioned spermathecal pores, $M$. formosae and M. yuhsii, was also tested using the SH test. The constrained topologies inferred from these monophyly hypotheses were compared with the topology of the ML tree derived from the combined

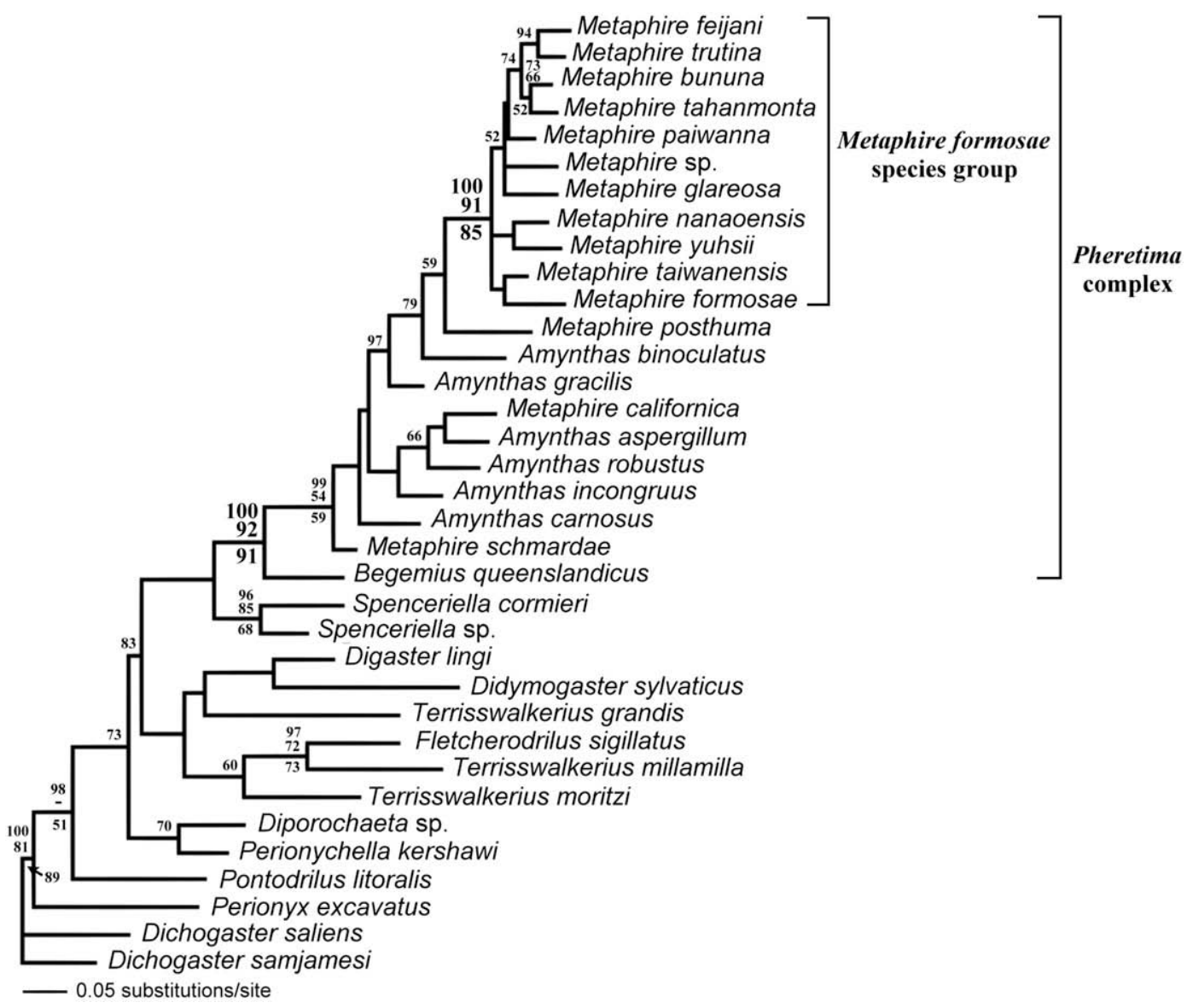

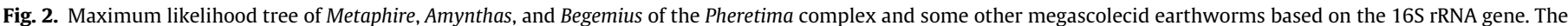

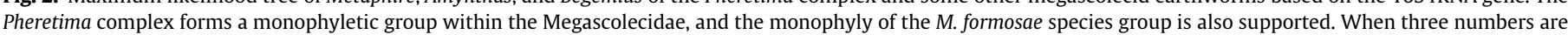

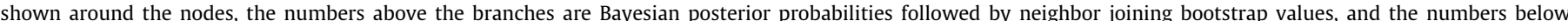

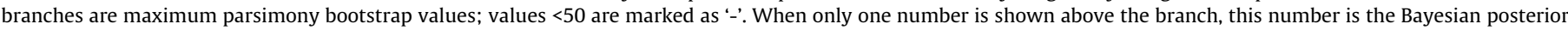

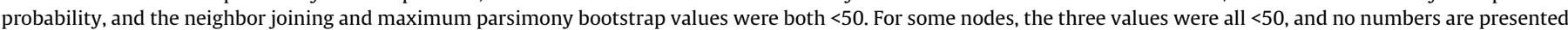




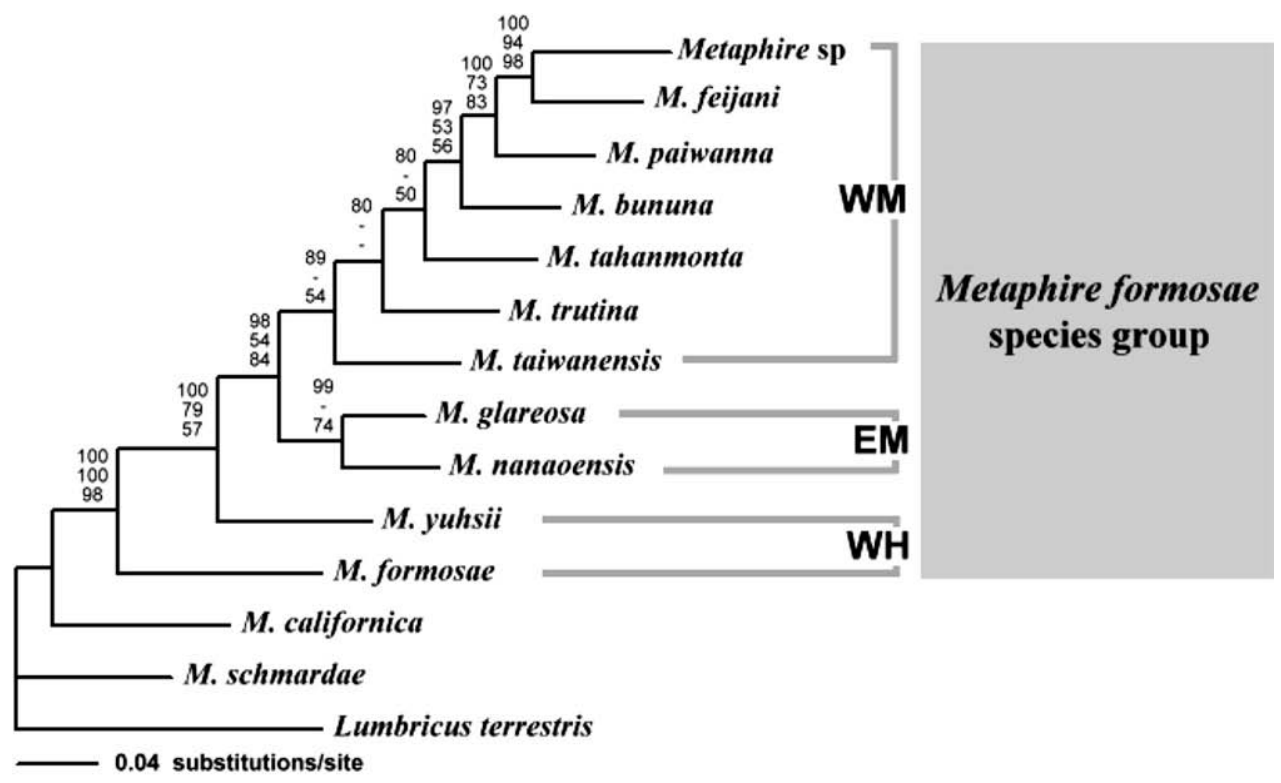

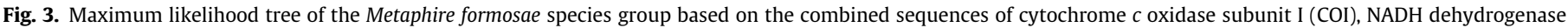

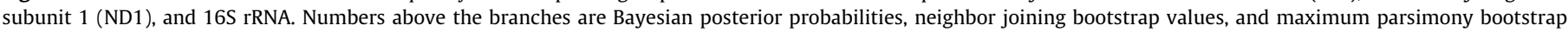

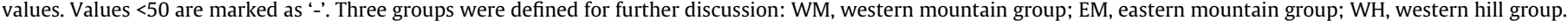

Table 5

Comparison of the ML tree $(\ln (L)$ score $=-13389.88)$ with the constraint trees using the Shimodaira-Hasegawa test

\begin{tabular}{llll}
\hline Topological constraint & $-\ln L$ & Diff. $-\ln L$ & $p$ value \\
\hline Monophyly of $M$. paiwanna and Metaphire sp. & 13406.37 & 16.49 & $0.02^{\mathrm{a}}$ \\
Monophyly of $M$. formosae and M. yuhsii & 13398.76 & 8.88 & $0.039^{\mathrm{a}}$ \\
\hline
\end{tabular}

a Topologies significantly worse than the ML tree $(\alpha=0.05)$.

analyses. The result indicated that all of the constrained topologies were significantly worse than those of the ML tree (Table 5).

\section{Discussion}

\subsection{Systematics of the M. formosae species group and the Pheretima complex}

According to the phylogenetic analyses, the $M$. formosae species group is composed of at least 11 species, including ten described species and a cryptic species previously identified as $M$. paiwanna paiwanna. In addition, the monophyly of the 11 species was strongly supported. Among them, M. formosae and M. yuhsii have spermathecal pores near the central dorsal lines, a rare feature in the Pheretima complex (Chang and Chen, 2005b). This unique feature, together with other similarities in morphology, resulted in our hypothesizing the monophyly of these two species. However, this hypothesis was rejected by the $\mathrm{SH}$ test. Similarly, although Metaphire sp. is a cryptic species morphologically similar to $M$. $p$. paiwanna, the monophyly of the two species was also rejected by the SH test.

Metaphire sp. is morphologically similar to $M$. p. paiwanna. However, this species has a smaller body size, less apparent horizontal ridges in the male pore areas, and more regularly coiled spermathecal diverticulum stalks. In addition, the two species require different habitats: M. p. paiwanna lives in evergreen broadleaf forests, while Metaphire sp. lives in deciduous broadleaf forests at higher elevations where $M$. p. paiwanna has never been found (Fig. 4).
In the original description, $M$. bununa glareosa was described based on four specimens, but these specimens were destroyed in a strong earthquake on 21 September 1999 that devastated central Taiwan. Our phylogenetic analyses do not support the monophyly of $M$. b. bununa and $M$. b. glareosa. On the contrary, two independent monophyletic groups corresponding to $M$. b. bununa and $M$. b. glareosa are supported (Figs. 1 and 3). Moreover, the average genetic distances between the two taxa are equivalent to those among species (Table 3). Therefore, $M$. $b$. glareosa should be elevated to specific status, namely $M$. glareosa.

According to the phylogenetic analysis, M. hengchunensis, $M$. $p$. paiwanna and M. p. liliumfordi, which correspond to clades A1, A2 and $\mathrm{A} 3$ in Fig. 1, respectively, are supported to form a monophyletic group (Fig. 1). The genetic distances between $M$. hengchunensis and each of M. p. paiwanna and M. p. liliumfordi (9.5\% and $9.4 \%$, respectively), are almost equivalent to that between $M$. p. paiwanna and M. p. liliumfordi (8.3\%), and are obviously lower than interspecific distances within the $M$. formosae species group (Table 3). Morphologically, the type specimens of $M$. hengchunensis are almost indistinguishable from specimens of $M$. p. paiwanna examined in this study, except that the seminal grooves and oval pads in the male pore areas of $M$. hengchunensis are slightly degenerated. In addition, the three taxa show an allopatric distribution. Altogether, we strongly suggest that $M$. hengchunensis should be regarded as one of the subspecies of $M$. paiwanna, namely $M$. paiwanna hengchunensis.

In the $M$. formosae species group, $M$. trutina and $M$. tahanmonta are holandric (with two pairs of testes, one each in segments 10 and 11), while other species are proandric (with only one pair of testes in segment 10). There are two hypotheses with two steps of changes that may explain this character evolution. In one hypothesis, $M$. tahanmonta and $M$. trutina independently acquired the second pair of testes (Fig. 5, left). Alternatively, in the other equally parsimonious hypothesis, the common ancestor of $M$. tahanmonta and $M$. trutina acquired the second pair of testes, and then the common ancestor of M. bunina, M. paiwanna, M. feijani and Metaphire sp. lost it (Fig. 5, right). Although the predominance of holandry in pheretimoid earthworms implies that this character state may be plesiomorphic, a hypothesis generally accepted 


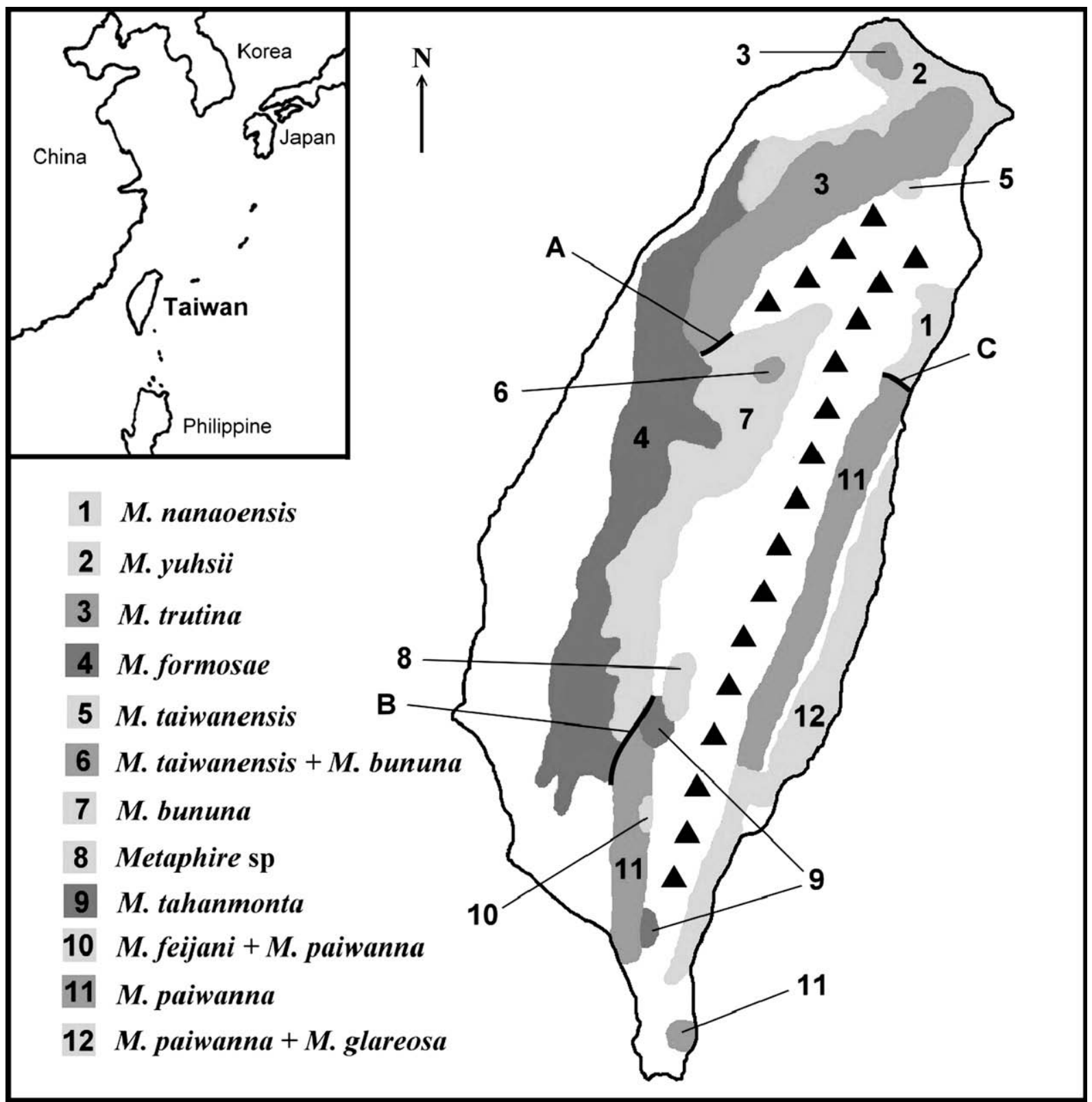

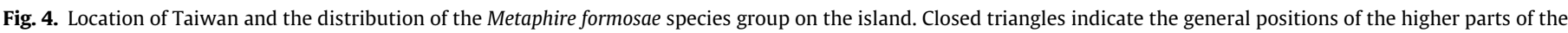

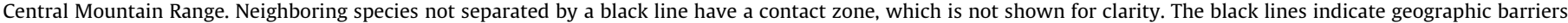
between species: A, Shuei-Shan Mountain Ridge; B, Launong River; C, Liwu River.

among earthworm taxonomists, the case of the $M$. formosae species group suggests that holandry can also be an apomorph. Moreover, the fact that testis condition changes even among closely related species indicates that this character is highly variable and cannot be used in grouping earthworm species within a genus. Therefore, the sub-grouping within a genus of the Pheretima complex, which is partly based on testis condition (Sims and Easton, 1972), may be inconsistent with the phylogeny. In addition, based on morphological phenetic analyses conducted about 30 years ago (Easton, 1979, 1982; Sims and Easton, 1972), the generic divisions in the Pheretima complex were recently challenged by overlapping diagnostic characters and serious homoplasy (Blakemore, 2002; James, 2005a). This opinion is further supported by the non-monophyly of Amynthas and Metaphire as revealed in the present study, as well as some other pheretimoid genera in previous DNA analyses (James, 2005b). All the evidence suggests the urgent need to revise the systematics of the Pheretima complex.

\subsection{Phylogeography}

Taiwan is a mountainous island about $170 \mathrm{~km}$ off the southeastern coast of China. The Central Mountain Range (CMR) runs northsouth throughout the center of the island, with more than 200 mountain peaks exceeding $3000 \mathrm{~m}$; along the southeast coast lies the Coastal Mountain Range, in which the majority of the mountain peaks are about $1000 \mathrm{~m}$. The main island of Taiwan is the result of a collision between the Luzon Volcanic Arc and the Eurasian Continental Margin between 5 and 2.5 million years ago (Ma), a geological event known as Penglai Orogeny (Huang et al., 1997, 2000; Teng, 1990;), and is still rising at present (Huang et al., 1997, 2000).

The mountains and the rivers in the CMR have long been considered as major factors resulting in intraspecific genetic differentiation of many terrestrial and freshwater animals in Taiwan, such as mice (Hsu et al., 2001), lizards (Liu, 1995), frogs 


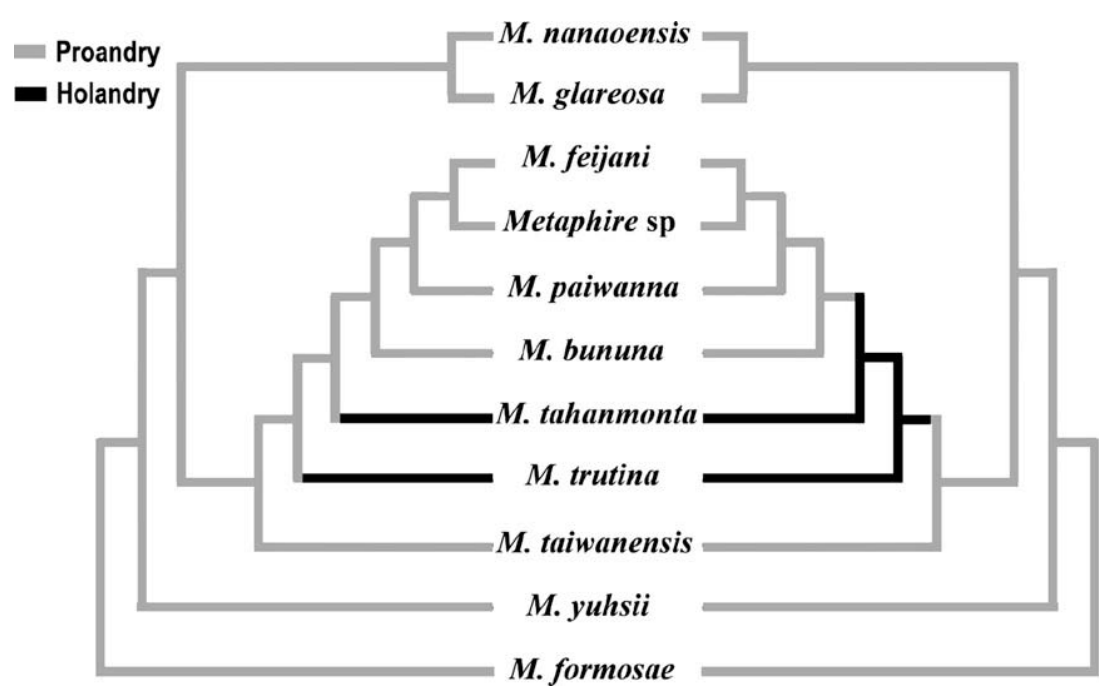

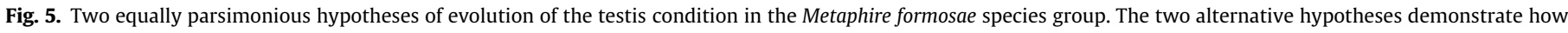

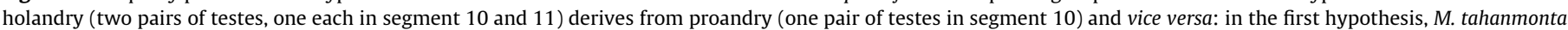

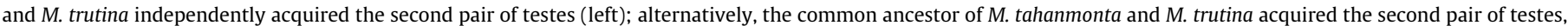
and then the common ancestor of M. bunina, M. paiwanna, M. feijani and Metaphire sp. lost it (right).

(Yang et al., 1994; Toda et al., 1997), spiders (Lin et al., 1999), crabs (Shih et al., 2006), and earthworms (Chang and Chen, 2005b). For instance, Chang and Chen (2005b) proposed that the formation of the ancient Tamsui River about $2.5 \mathrm{Ma}$ in northern Taiwan caused the divergence between the two populations of M. yuhsii (re-revealed as clades F1 and F2 in Fig. 1). Similarly, clades C1 and C2 of M. nanaoensis isolated by the Heping River in northeastern Taiwan shows another case of riverdriven genetic differentiation. Except the two cases of $M$. yuhsii and $M$. nanaoensis, intraspecific genetic differentiation has been observed among geographically isolated populations of four more species in the M. formosae species group, including $M$. paiwanna (clades A1 A3), M. glareosa (clades B1 B3), M. formosae (clades D1 D3), and M. taiwanensis (clades E1 and E2). This genetic structure is clear evidence that the formation of the mountains and the rivers in the CMR has resulted in intraspecific genetic differentiation in this species group.

In Taiwan, most species of the $M$. formosae species group are allopatrically distributed (Fig. 4). Furthermore, in the inferred phylogenetic tree, species of the eastern mountain group are distributed east of the CMR, those of the western mountain group are distributed west of the CMR, except M. paiwanna, and those of the western hill group are distributed in the western foothills to the west of the CMR (Figs. 3 and 4). This pattern suggests that allopatric speciation may be the major mechanism driving the species diversity of this group. Using the estimated formation time of the ancient Tamsui River and the genetic divergence within M. yuhsii (Table 4), we can roughly estimate the evolutionary rate of earthworm COI genes as $4.8 \%$ per million years, and consequently, the speciation events of the $M$. formosae species group are estimated to have occurred between 5.8 and $2.7 \mathrm{Ma}$. This inferred time range is congruent with the period of the Penglai Orogeny, during which the rapidly formed mountains and rivers were geographical barriers for many flightless invertebrates. Therefore, by combining the geological and phylogenetic evidence, we herein propose a vicariance hypothesis to explain the allopatric speciation events of the $M$. formosae species group. In this hypothesis, the ancestors of these species arrived in Taiwan before the rapid uplift of this island, probably during the late Miocene, and then dispersed throughout this island. During the period of rapid uplift between 5.0 and $2.5 \mathrm{Ma}$, different populations of the ancestral species were rapidly isolated by the mountains and the rivers that formed due to orogenesis. This isolation resulted in genetic differentiation and ultimately caused speciation of the $M$. formosae species group.

The endemic land fauna diversity in Taiwan was generally attributed to be consequences of multiple dispersal-isolation events between Taiwan and the surrounding regions (Lin et al., 2002; Ota, 1997; Ota et al., 2002; Tu et al., 2000; Yeh et al., 2004), while the contribution of the CMR and vicariance events during Penglai Orogeny to speciation of animals on this island has never been well investigated before. Our present study is the first case that demonstrates within-island speciation of animals through vicariance events caused by orogenesis in Taiwan. Considering the diverse endemic invertebrate fauna awaiting being discovered and investigated, the present case may be one of the tremendous amounts of similar stories among the endemic fauna on this island.

\section{Acknowledgments}

We are grateful to the persons who kindly assisted us in the collection of earthworm samples. We are also grateful to Drs. S. James, C.-F. Tsai and H.-P. Shen and Mr. C.-C. Huang for their helpful comments on the manuscript. This study was supported by the National Science Council of Taiwan (NSC92-2621-B-002-019) to J.H. Chen.

\section{References}

Blakemore, R.J., 2002. Cosmopolitan Earthworms-An Eco-Taxonomic Guide to the Peregrine Species of the World. (First CD ed.). VermEcology, PO BOX 414 Kippax, ACT 2615, Australia.

Blakemore, R.J., 2004. Checklist of pheretimoid earthworms after Sims and Easton, 1972. In: Moreno, A., Borges, S. (Eds.), Avances en Taxonomia de Lombrices de Tierra/Advances in Earthworm Taxonomy (Annelida: Oligochaeta). Editorial Complutense, Universidad Complutense, Madrid, Spain, pp. 126-154.

Blakemore, R.J., Chang, C.-H., Chuang S.-C., Ito, M.T., James, S.W., Chen, J.-H., 2006 Biodiversity of earthworms in Taiwan: a species checklist with the confirmation and new records of the exotic lumbricids Eisenia fetida and Eiseniella tetraedra. Taiwania 51, 226-236.

Chang, C.-H., Chen, J.-H., 2004. A new species of earthworm belonging to the genus Metaphire Sims and Easton 1972 (Oligochaeta: Megascolecidae) from southern Taiwan. Taiwania 49, 219-224.

Chang, C.-H., Chen, J.-H., 2005a. Three new species of octothecate pheretimoid earthworms from Taiwan, with discussion on the biogeography of related species. J. Nat. Hist. 39, 1469-1482. 
Chang, C.-H., Chen, J.-H., 2005b. Taxonomic status and intraspecific phylogeography of two sibling species of Metaphire (Oligochaeta: Megascolecidae) in Taiwan. Pedobiologia 49, 591-600.

Chang, C.-H., Lin, Y.-H., Chen, I.-H., Chuang, S.-C., Chen, J.-H., 2007. Taxonomic reevaluation of the Taiwanese montane earthworm Amynthas wulinensis Tsai, Shen and Tsai, 2001 (Oligochaeta: Megascolecidae): polytypic species or species complex? Org. Divers. Evol. 7, 231-240.

Easton, E.G., 1979. A revision of the "acaecate" earthworms of the Pheretima group (Megascolecidae: Oligochaeta): Archipheretima, Metapheretima, Planapheretima, Pleionogaster, and Polypheretima. Bull. Br. Mus. Nat. Hist. (Zool.) 35, 1-126.

Easton, E.G., 1982. Australian pheretimoid earthworms (Megascolecidae: Oligochaeta): A synopsis with the description of a new genus and five new species. Aust. J. Zool. 30, 711-735.

Farris, J.S., Kallersjo, M., Kluge, A.G., Bult, C., 1994. Testing significance of incongruence. Cladistics 10,315-320.

Folmer, O., Back, M., Hoeh, W., Lutz, R., Vrijenhoek, R., 1994. DNA primers for amplification of mitochondrial cytochrome c oxidase subunit I from diverse metazoan invertebrates. Mar. Biol. Biotechnolog. 3, 294-299.

Hall, T.A., 1999. BioEdit: a user-friendly biological sequence alignment editor and analysis program for Windows 95/98/NT. Nucleic acids Res. Symp. Ser. 41, 9598.

Hebert, P.D.N., Cywinska, A., Ball, S.L., deWaard, J.R., 2003a. Biological identifications through DNA barcodes. Proc. R. Soc. B 270, 313-321.

Hebert, P.D.N., Ratnasingham, S., deWaard, J.R., 2003b. Barcoding anomal life: cytochrome c oxidase subunit 1 divergences among closely related species. Proc. R. Soc. B 270 (Suppl.), S96-S99.

Heethoff, M., Etzold, K., Scheu, S., 2004. Mitochondrial COII sequences indicate that the parthenogenetic earthworm Octolasion tyrtaeum (Savigny 1826) constitutes of two lineages differing in body size and genotype. Pedobiologia 48, 9-13.

Hillis, D., Moritz, C., 1990. Molecular Systematics. Sinauer, Sunderland, MA.

Hsu, F.-H., Lin, F.-J., Lin, Y.-S., 2001. Phylogeographic structure of the Formosan wood mouse, Apodemus semotus Thomas. Zool. Stud. 40, 91-102.

Huang, C.-Y., Wu, W.-Y., Chang, C.-P., Tsao, S., Yuan, P.B., Lin, C.-W., Kuan-Yuan, X., 1997. Tectonic evolution of accretionary prism in the arc-continent collision terrane of Taiwan. Tectonophysics 281, 31-51.

Huang, C.-Y., Yuan, P.B., Lin, C.-W., Wang, T.K., Chang, C.-P., 2000. Geodynamic processes of Taiwan arc-continent collision and comparison with analogs in Timor, Papua New Guinea, Urals and Corsica. Tectonophysics 325, 1-21.

Huelsenbeck, J.P., Ronquist, F.R., 2001. MRBAYES: Bayesian inference of phylogenetic trees. Bioinformatics 17, 754-755.

James, S.W., 2005a. New genera and species of pheretimoid earthworms (Clitellata: Megascolecidae) from southern Luzon, Philippines. Syst. Biodivers. 2, 271-279.

James, S.W., 2005b. Preliminary molecular phylogeny in the Pheretima group of genera (Crassiclitellata: Megascolecidae) using Bayesian analysis. In: Pop, V.V., Pop, A.A. (Eds.), Advances in earthworm taxonomy II (Annelida: Oligochaeta). Cluj University Press, Cluj-Napoca, Romania, pp. 129-142.

James, S.W., Shih, H.-T., Chang, H.-W., 2005. Seven new species of Amynthas (Clitellata: Megascolecidae) and new earthworm records from Taiwan. J. Nat. Hist. 39, 1007-1028.

Jamieson, B.G.M., Tillier, S., Tillier, A., Justine, J.L., Ling, E., James, S., McDonald, K., Hugall, A.F., 2002. Phylogeny of the Megascolecidae and Crassiclitellata (Annelida, Oligochaeta): combined versus partitioned analysis using nuclear (28S) and mitochondrial (12S, 16S) rDNA. Zoosystema 24, 707-734.

Lin, C.-H., Lee, C.-N., Yang, C.-C., Lue, B.-W., Chen, S.-H., Fang, K., 1999. RAPDestimated genetic relationship of Psechrid spiders (Araneae: Psechrus) in Taiwan. Biol. Bull. Nat. Taiwan Nor. Univers. 34, 95-104 (in Chinese).

Lin, S.-M., Chen, C.-L., Lue, K.-Y., 2002. Molecular phylogeny and biogeography of the grass lizards genus Takydromus (Reptilia: Lacertidae) of East Asia. Mol. Phylogenet. Evol 22, 276-288.

Liu, K.-C., 1995. Phylogeographic relationship of Japalura swinhonis based on analysis of mtDNA. Master thesis, National Sun Yat-Sen University, Kaohsiung, Taiwan (in Chinese)

Michaelsen, W., 1922. Oligochaeten aus dem Rikks Museum van Natuurlijke Historie zu liden. Capita Zool. 1, 1-72 (in German).

Ota, H., 1997. Historical biogeographical implications in the variation and diversity of amphibians and reptiles in Taiwan. In "The Symposium on the Phylogeny, Biogeography and Conservation of Fauna and Flora of East Asian Region," National Taiwan Normal University, Taipei, Taiwan, pp. 75-86.

Ota, H., Honda, M., Chen, S.-L., Hikida, T., Panha, S., Oh, H.-S., Matsui, M., 2002. Phylogenetic relationships, taxonomy, character evolution and biogeography of the lacertid lizards of the genus Takydromus (Reptilia: Squamata): a molecular perspective. Biol. J. Linnean Soc. 76, 493-509.
Palumbi, S., Martin, R.A., Romano, S., McMillan, W.O., Stice, L., Grabowski, G., 1991. The Simple Fool's Guide to PCR, Vers. 2. University of Hawaii Zoology Department, Honolulu, HI.

Pérez-Losada, M., Eiroa, J., Mato, S., Domínguez, J., 2005. Phylogenetic species delimitation of the earthworms Eisenia fetida (Savigny, 1826) and Eisenia andre Bouché, 1972 (Oligochaeta, Lumbricidae) based on mitochondrial and nuclear DNA sequences. Pedobiologia 49, 317-324.

Pop, A.A., Cech, G., Wink, M., Csuzdi, C., Pop, V.V., 2007. Application of 16S, 18S rDNA and COI sequences in the molecular systematics of the earthworm family Lumbricidae (Annelida, Oligochaeta). Eur. J. Soil Biol. 43, S43-S52.

Pop, A.A., Wink, M., Pop, V.V., 2003. Use of 18S, 16S rDNA and cytochrome c oxidase sequences in earthworm taxonomy (Oligochaeta, Lumbricidae). Pedobiologia 47, 428-433.

Posada, D., Crandall, K.A., 1998. Modeltest: testing the model of DNA substitution. Bioinformatics $14,817-818$.

Rodríguez, F., Oliver, J.F., Martín, A., Medina, J.R., 1990. The general stochastic model of nucleotide substitutions. J. Theor. Biol. 142, 485-501.

Ronquist, F.R., Huelsenbeck, J.P., 2003. MrBAYES 3: Bayesian phylogenetic inference under mixed models. Bioinformatics 19, 1572-1574.

Shih, H.-T., Hung, H.-C., Schubart, C.D., Chen, C.A., Chang, H.-W., 2006. Intraspecific genetic diversity of the endemic freshwater crab Candidiopotamon rathbunae (Decapoda, Brachyura, Potamidae) reflects five million years of the geological history of Taiwan. J. Biogeogr. 33, 980-989.

Shimodaira, H., Hasegawa, M., 1999. Multiple comparisons of log-likelihoods with applications to phylogenetic inference. Mol. Biol. Evol. 16, 1114-1116.

Sims, R.W., Easton, E.G., 1972. A numerical revision of the earthworm genus Pheretima auct. (Megascolecidae: Oligochaeta) with the recognition of new genera and an appendix on the earthworms collected by the Royal Society North Borneo Expedition. Biol. J. Linnean Soc. 4, 169-268.

Swofford, D.L., 2000. PAUP 4.0: Phylogenetic Analysis Using Parsimony (and Other Methods). Sinauer, Sunderland, MA.

Tamura, K., Nei, M., 1993. Estimation of the number of nucleotide substitution in the control region of mitochondrial DNA in humans and chimpanzees. Mol. Biol. Evol. 10, 512-526.

Tavaŕe, S., 1986. Some probabilistic and statistical problems in the analysis of DNA sequences. In: Miura, R.M. (Ed.), Some Mathematical Questions in Biology-DNA Sequence Analysis. American Mathematical Society, Providence, Rhode Island, pp. 57-86.

Teng, L.S., 1990. Geotectonic evolution of late Cenozoic arc-continent collision in Taiwan. Tectonophysics 183, 57-76.

Thompson, J.D., Gibson, T.J., Plewniak, F., Jeanmougin, F., Higgins, D.G., 1997 The CLUSTAL_X windows interface: flexible strategies for multiple sequence alignment aided by quality analysis tools. Nucleic Acids Res. 25, 48764882.

Toda, M., Nishida, M., Matsui, M., Wu, G.F., Ota, H., 1997. Allozyme variation among East Asian populations of the Indian rice frog, Rana limnocharis (Amphibia: Anura). Biochem. Syst. Ecol. 25, 143-159.

Tsai, C.-F., 1964. On some earthworms belonging to the genus Pheretima Kinberg collected from Taipei area in north Taiwan. Q. J. Taiwan Mus. 17, 1-35.

Tsai, C.-F., Chen, J.-H., Tsai, S.-C., Shen, H.-P., 2003. A new species of the earthworm belonging to the genus Metaphire Sims and Easton (Megascolecidae: Oligochaeta) from the northeastern Taiwan. Endemic Species Res. 5, 83-88.

Tsai, C.-F., Shen, H.-P., Tsai, S.-C., 2000a. Native and exotic species of terrestria earthworm (Oligochaeta) in Taiwan with reference to Northeast Asia. Zool. Stud. 39, 285-294.

Tsai, C.-F., Tsai, S.-C., Liaw, G.-J., 2000b. Two new species of pontandric pheretimoid earthworms belonging to the genus Metaphire (Megascolecidae: Oligochaeta) from Taiwan. J. Nat. Hist. 34, 1731-1741.

Tsai, C.-F., Tsai, S.-C., Shen, H.-P., 2004. A new gigantic earthworm of the genus Metaphire Sims and Easton (Megascolecidae: Oligochaeta) from Taiwan with reference to evolutional trends in body sizes and segment numbers of the Pheretima genus-group. J. Nat. Hist. 38, 877-887.

Tu, M.-C., Wang, H.-Y., Tsai, M.-P., Toda, M., Lee, W.-J., Zhang, F.-J., Ota, H., 2000. Phylogeny, taxonomy, and biogeography of the oriental pitvipers of the genus Trimeresurus (Reptilia: Viperidae: Crotalinae): a molecular perspective. Zool. Sci. 17, 1147-1157.

Yang, Y.-J., Lin, Y.-S., Wu, J.-L., Hui, C.-F., 1994. Variation in mitochondrial DNA and population structure of the Taipei treefrog Rhacophorus taipeianus in Taiwan. Mol. Ecol. 3, 219-228.

Yeh, W.-B., Chang, Y.-L., Lin, C.-H., Wu, F.-S., Yang, J.-T., 2004. Genetic differentiation of Loxoblemmus appendicularis complex (Orthoptera: Gryllidae): speciation through vicariant and glaciation events. Ann. Entomol. Soc. Am. 97, 613-623. 